\section{DBPCFC bei Verdacht auf Nahrungsmittelallergie?}

- Ist die doppelblinde, placebokontrollierte Provokation auf Nahrungsmittel (DBPCFC) beim Verdacht auf Nahrungsmittelallergie bei Kindern wirklich nötig? $82 \%$ der Anwesenden im Saal stimmten zu Beginn der Pro- und Kontrasitzung mit Prof. Dr. Bodo Niggemann, Berlin, damit überein. Andere Parameter könnten zwar Hinweise liefern, jedoch keinen echten Beweis. Die Aussagekraft von Haut-Pricktest und spezifischem IgE im Serum erwies sich bei Nahrungsmitteln oft genug als unzureichend. Demnach funktionieren die $95 \%$ "decision points" nur für Hühnerei. Da selbst bei Ara $2 \mathrm{~h}$ nur rund $10 \%$ der Kinder oberhalb des $95 \%$ "decision point “ liegen, benötigten neun von zehn einen Provokationstest.
Eine vorbereitete orale Provokation sei allemal sicherer als eine, die die Kinder unvorbereitet trifft. Während die orale Provokation in der Klinik ärztlich überwacht in langsam steigenden Dosen vorgenommen wird, finde der Kontakt mit dem allergieauslösenden Nahrungsmittel in „freier Wildbahn“ unkontrolliert statt; notärztliche Hilfe komme hier erst nach Anruf und mit Zeitverzug. Ohne orale Provokation in der Klinik gebe es keine Sicherheit für Kinder, so Niggemann.

Dem begegnete Dr. Thomas Spindler, Wangen/Allgäu, mit dem Argument der eindeutigen Symptome: Klare, rasch eintretende Symptomatik, die in einer gut geführten Anamnese mit vernünftigen Eltern herausgearbeitet wird, könnten die DBPCFC über- flüssig machen. Bei eindeutigen Reaktionen, Sofortreaktionen und anaphylaktischen Reaktionen könne weniger aufwändig, schneller und offen provoziert werden. Und auch bei offensichtlich gesunden Kindern ohne Mangelerscheinungen, die sich einem Test unterziehen wollen, sei der zeitliche, personelle und finanzielle Aufwand für den Nachweis einer Allergie auf ein Nahrungsmittel mittels DBPCFC schlicht zu hoch.

Dank der Moderatorin PD Dr. Doris Staab, Berlin, konnten sich die Kontrahenten letztlich darauf einigen, dass für die Indikation zur DBPCFC eine Differenzierung nötig ist. Bei eindeutigen Befunden könne auf den aufwändigen Test verzichtet werden, ansonsten müsse individuell entschieden werden.

Kathrin von Kieseritzky

AllergoArena „DBPCFC: Nötig und sicher?”

\section{Weniger Exposition ist keine Lösung}

— Bei berufsbedingten allergischen Atemwegserkrankungen möchten Betroffene trotz ihrer Symptome oft ihren Arbeitsplatz behalten. Die Verringerung der Allergenexposition oder die medikamentöse Therapie verhin-

Selbst bei einem Arbeitsplatzwechsel und der völligen Allergenkarenz nach einem positiven Hauttest entwickeln sensibilisierte Personen in Einzelfällen im Verlauf noch Asthma, wie Prof. Dr. Rolf Merget, Bochum, in einer Studie zur Prävention eines platinsalzabhängigen Asthmas in einem Unternehmen der Degussa feststellen musste. Besteht erst einmal ein berufsbezogenes dern die Asthmaentwicklung aber nicht.
Asthma, ist die Allergenreduktion in vielen Branchen zwar gang und gäbe. Verschiedene Studien haben aber gezeigt, dass die alleinige Allergenreduktion mit einer höheren Persistenz und häufig auch mit einer Verschlechterung der Asthmasymptome einhergeht. „Je länger jemand mit berufsbedingten allergischen Beschwerden an seinem Arbeitsplatz bleibt, umso schlechter werden die Symptome", ist auch die Erfahrung von Merget. „Wenn man jemanden aus dieser Exposition herausnimmt, wird es besser - oft auch noch nach Jahren."

Wenn Betroffene dennoch an ihrem Arbeitsplatz bleiben möchten, rät er zu einer ent- sprechenden Aufklärung über die möglichen Folgen der alleinigen Reduktion oder rein symptomatischer Behandlung. Ein berufsbedingtes Asthma verhindern kann man aber wohl nur durch frühzeitige Erfassung einer Sensibilisierung mit der Konsequenz der Versetzung an einen allergenfreien Arbeitsplatz. Bei bereits bestehenden asthmatischen Symptomen kann mit der Karenz bestenfalls ein Progress der Erkrankung verhindert werden. „In Deutschland erfolgt eine Versetzung aber erst bei Symptomen, nicht bei einem positiven Pricktest - da kommen wir zu spät!" Friederike Klein

AllergoPlenum: „Berufliche und umweltbedingte Atemwegserkrankungen: Rationelle Diagnostik und rationaler Umgang"

ziierten Nebenwirkungen kam [Steyn E et al. Int J Emerg Med 2013;6:7). Das Problem: Es ließen sich nicht ausreichend Patienten für die Studie rekrutieren.

„Aber die Geräte gibt es bereits in Europa - zugelassen für die Behandlung der Migräne", berichtete Fischer. Er präferierte die Weiterentwicklung des "Electroceuticals", wie er es nannte, eher für leichtere Asthmaformen oder zur Prophylaxe von Exazerbationen.

Friederike Klein

AllergoCompact: „Allergie vom Sofort- bis Spättyp: Alles eine Sache der Nerven?" 